\title{
Albinism in F1 Hybrids Hinders Geneflow Between Cultivated Chickpea (Cicer arietinum L.) and the Tertiary Gene Pool Species, Cicer Pinnatifidum
}

Shivali Sharma ( $\nabla$ shivalipbg@gmail.com )

Global Crop Diversity Trust https://orcid.org/0000-0001-5314-484X

Shivaji Ajinath Lavale

ICRISAT: International Crops Research Institute for the Semi-Arid Tropics

Benjamin Kilian

Global Crop Diversity Trust

\section{Research Article}

Keywords: Cicer pinnatifidum, chickpea, geneflow, tertiary gene pool, cross-incompatibility

Posted Date: December 6th, 2021

DOI: https://doi.org/10.21203/rs.3.rs-1134524/v1

License: (c) (1) This work is licensed under a Creative Commons Attribution 4.0 International License. Read Full License 


\section{Abstract}

Wild Cicer species, especially those in the tertiary gene pool, carry useful alleles for chickpea improvement. The aim of this study was to evaluate the crossability and geneflow between three chickpea cultivars (as female parents) and four cross-incompatible Cicer pinnatifidum accessions (as pollen parents) from the tertiary gene pool. Ten crosses were conducted. One fully developed healthy $\mathrm{F}_{1}$ seed was harvested in vivo from the ICC $4958 \times$ ICC 17269 cross, but the seedling developed an albino phenotype at 4-5 days after germination. Unlike other crosses, those involving the cultivar ICCV 96030 generated a large number of pods with comparatively large ovules. One albino plantlet was obtained from the ICCV $96030 \times$ ICC 17269 cross by embryo rescue. Crosses involving ICCV 10 resulted in flower drop and poor pod set. These variable genotype-specific responses of pod, ovule, and seed development indicate that genetic factors affect the formation of interspecific hybrids. Although pod and seed formation in these interspecific crosses can be improved, geneflow between these materials is hindered by a strong genetic factor conferring albinism in the $\mathrm{F}_{1}$ hybrids.

\section{Key Message}

Pod, ovule, and seed development vary in crosses between chickpea and C. pinnatifidum, indicating that genetic factors affect hybrid formation. Albinism of $F_{1}$ hybrids restricts geneflow between these materials.

\section{Introduction}

Chickpea (Cicer arietinum L.), the second most important dietary legume after common bean, is a rich source of proteins, carbohydrates, micronutrients, and vitamins (Jukanti et al. 2012). It is a potential staple food crop in about 55 countries. India is the largest producer of chickpea with an annual production of 9.9 million tonnes (FAOSTAT 2019). Chickpea production worldwide is affected by biotic and abiotic stresses. Because there is limited genetic variation in the cultivated chickpea germplasm, it is necessary to utilize wild Cicer species for genetic improvement. Wild Cicer species are strongly resistant to major biotic stresses like Ascochyta blight (Stamigna et al. 2000; Collard et al. 2001; Croser et al. 2003; Rao et al. 2003; Shah et al. 2005; Pande et al. 2006), Botrytis gray mold (Stevenson and Haware 1999; Rao et al. 2003; Pande et al. 2006), and Fusarium wilt (Infantino et al. 1996; Croser et al. 2003; Rao et al. 2003), and tolerant to abiotic stresses such as drought (Croser et al. 2003; Kashiwagi et al. 2005; Toker et al. 2007), cold (Croser et al. 2003; Toker 2005; Berger et al. 2012), and combined drought and heat (Canci and Toker 2009). Wild Cicer species also have desirable nutrition-related traits such as high seed protein and mineral contents (Rao et al. 2003; Sharma et al. 2021).

Various incompatibility barriers, linkage drag, and poor viability and sterility of $F_{1}$ hybrids and progenies mean that potential wild Cicer species are underutilized in chickpea breeding programs. Two annual wild Cicer species, Cicer reticulatum and Cicer echinospermum, are crossable with cultivated chickpea. However, the sterility of $F_{1}$ hybrids and progenies has limited the utilization of $C$. echinospermum in crossing programs. Little is known about the crossability of the other six annual wild Cicer species with cultivated chickpea. To utilize those species in chickpea improvement, specialized techniques such as the application 
of growth hormones, ovule culture, and embryo rescue are required (Badami et al. 1997; Mallikarjuna 1999; Mallikarjuna and Jadhav 2008; Lulsdorf et al. 2005).

Few attempts have been made to generate interspecific hybrids between Cicer arietinum from the primary gene pool and wild Cicer pinnatifidum from the tertiary gene pool (Badami et al. 1997; Mallikarjuna and Jadhav 2008). Systematic crossing efforts involving diverse parental combinations are required to advance the production of viable interspecific hybrids involving tertiary gene pool species. The aim of this study, therefore, was to evaluate the crossability and geneflow between three cultivars of $C$. arietinum and four wild $C$. pinnatifidum accessions originating/collected from Turkey and Syria.

Three chickpea cultivars (ICCV 10, ICC 4958, and ICCV 96030) and four wild accessions (ICC 17126, ICC 17276 , ICC 17200, and ICC 17269) belonging to the tertiary gene pool species $C$. pinnatifidum were used (Table 1). The seeds of all wild accessions were scarified by incising the hard seed coat. All seeds were treated with fungicides ( $2 \mathrm{~g}$ thiram $+1 \mathrm{~g}$ carbendazim $\mathrm{kg}^{-1}$ seed) before sowing in pots in a 2:1:1 mixture of sterilized black soil, farmyard manure, and sand. Seed sowing was staggered to synchronize the flowering of cultivated genotypes and wild accessions. At 1 month after germination, $C$. pinnatifidum seedlings were exposed to an 18-h light/6-h dark photoperiod with light supplied by $60-\mathrm{W}$ incandescent lights to induce early flowering (Sharma and Upadhyaya 2019). Interspecific crosses were made using the three cultivars as female parents and the four wild accessions as pollen parents. ICCV 10 and ICC 4958 were each crossed with all four $C$. pinnatifidum accessions, and ICCV 96030 was crossed only with two accessions, ICC 17126 and ICC 17269. The flower buds of the female parents were emasculated and tagged between 3:00 p.m. and 4:00 p.m., and then pollinated with fresh pollen from wild accessions the following morning between 8:00 a.m. and 9:00 a.m. Each day for 3 consecutive days, a mixture of growth hormones (50 $\mathrm{mg} \mathrm{L}^{-1}$ gibberellic acid $+10 \mathrm{mg} \mathrm{L}^{-1}$ naphthalene acetic acid $+10 \mathrm{mg} \mathrm{L}^{-1}$ kinetin, 1:1:1) was applied to the base of the peduncle of the pollinated buds to prevent flower drop and pod abscission. Selfed pods on the same branch were removed to encourage growth of the crossed pods. We recorded the number of pollinations and number of fully developed pods generated in each cross (Table 2).

Yellowing pods were harvested and the ovules were cultured in liquid Murashige and Skoog (MS) medium containing $3 \% \mathrm{w} / \mathrm{v}$ sucrose, $0.25 \mathrm{mg} / \mathrm{L}$ indole acetic acid, and $1 \mathrm{mg} / \mathrm{L}$ zeatin. After 3 weeks, the cultured ovules were subcultured into fresh ovule culture medium and cultured until the embryos emerged from the ovules. The embryos were transferred to shoot growth medium (liquid MS containing $3 \% \mathrm{w} / \mathrm{v}$ sucrose, 0.25 $\mathrm{mg} / \mathrm{L}$ indole acetic acid, and $1 \mathrm{mg} / \mathrm{L}$ kinetin). Well-grown shoots were cultured on root-induction medium (half-strength MS basal salts, $1.5 \% \mathrm{w} / \mathrm{v}$ sucrose, and $0.5 \mathrm{mg} / \mathrm{L}$ indole butyric acid). We recorded the number of ovules cultured and number of plantlets generated through ovule culture (Table 2).

One fully mature pod with a healthy $F_{1}$ seed was harvested from the ICC $4958 \times$ ICC 17269 cross. The $F_{1}$ seed resembled that of the cultivated parent (ICC 4958) with respect to size, color, texture, and shape. The mature $F_{1}$ seed was sown in a mixture of soil, sand, and vermiculite (3:1:1). The $F_{1}$ seedling had a leaf shape similar to that of the wild $C$. pinnatifidum parent ICC 17269 , confirming true hybridity (Figure 1 ). Thus, the generation of a healthy and functional $F_{1}$ seed in the ICC $4958 \times$ ICC 17269 cross was not prevented by pre-fertilization barriers such as failure of pollen germination, pollen incompatibility, arrested pollen tube 
growth in the stigma or style, failure of the pollen tube to penetrate the ovule, or arrested growth of the pollen tube within the ovule; or by post-fertilization barriers such as embryo abortion, or shriveled or immature $F_{1}$ seeds. However, this seedling became albino (lacked chlorophyll) at $4-5$ days after germination (Figure 1). This albinism is attributed to defective chloroplasts with poorly developed thylakoids and few and disorganized grana (Badami et al. 1997; Clarke et al. 2011). Our attempts to multiply this albino-type plant by regeneration through callus induction and culture of different explants (leaves, stem cuttings, and nodes) on basal MS medium containing $0.5 \mathrm{mg} / \mathrm{L}$ benzylaminopurine and 0.5 $\mathrm{mg} / \mathrm{L}$ naphthalene acetic acid were unsuccessful. Thus, although geneflow in the ICC $4958 \times$ ICC 17269 cross was not hindered by the pre- or post-fertilization barriers reported elsewhere (Badami et al. 1997; Ahmad and Slinkard 2004; Mallikarjuna and Jadhav 2008; Clarke et al. 2011), it was hindered by the albinism of $F_{1}$ hybrid plants. It will be possible to generate more healthy $F_{1}$ pods and seeds from this cross by increasing the number of pollinations and using different combinations of plant growth hormones. However, efforts are needed to address the problem of albinism in $F_{1}$ seedlings.

Unlike other crosses, interspecific crosses involving ICCV 96030 resulted in fully developed, mature pods (Table 2). However these pods lacked mature seeds. Most of the pods contained minute to small-sized colorless ovules. Thus, the pods developed normally but the ovules inside did not (Figure 2).

Pod development begins after fertilization. In this study, C. pinnatifidum pollen successfully fertilized ICCV 96030 , leading to the differentiation of the ovary into the pod wall. However, ovules did not successfully differentiate into seeds due to some intrinsic reasons. This kind of hybrid embryo response has not been reported for other chickpea interspecific crosses. The incompatibility between cultivated chickpea ICC 96030 and all the $C$. pinnatifidum accessions used in this study is due to a post-zygotic barrier, specifically defective embryos that could not develop into functional seeds. Post-zygotic barriers hindering interspecific hybridization between $C$. arietinum and $C$. pinnatifidum have also been reported by Badami et al. (1997). Of the three cultivated chickpea cultivars, ICCV 96030 yielded the highest number of mature, fully developed pods, including a few with enlarged embryos, when pollinated with $C$. pinnatifidum. It will be possible to harvest mature pods with seeds from ICCV $96030 \times$ C. pinnatifidum crosses by increasing the number of pollinations in each cross, adjusting plant growth hormone treatments to facilitate embryo/seed development, by crossing in different directions, and/or by using other $C$. pinnatifidum accessions, e.g., ICC 17276 and ICC 17200, as the pollen parent. In addition, immature embryos can be rescued by ovule culture.

The aborting ovules were cultured from 7-8 days after pollination. The tiny ovules did not grow upon culturing, but one larger ovule (derived from ICCV $96030 \times$ ICC 17269) grew normally and the embryo regenerated into a seedling (Figure 2). Although the shoot was initially green, the newly formed leaves lacked chlorophyll and the albino seedling died after 2 weeks. Defective chloroplasts are the major barrier in generating interspecific hybrids between $C$. arietinum and C. pinnatifidum (Clarke et al. 2011). In the crosses involving ICCV 10, flower drop was the major obstacle. Most of the pollinated flower buds dropped within 12 days of pollination, despite the use of plant growth hormones. Although some cross combinations formed a few pods, they turned yellow within 3-4 days of pollination, and ovules from these pods did not develop further in vitro because of their small size. 
Interspecific hybridization between chickpea cultivars and $C$. pinnatifidum produced one fully mature $F_{1}$ seed (from ICC $4958 \times$ ICC 17269). None of the other cross combinations yielded fully mature $F_{1}$ seeds. Although ICCV 96030 formed the most pods, followed by ICC 4958, only one ovule from the ICCV $96030 \times$ ICC 17269 cross regenerated into a plantlet in ovule culture. None of the three chickpea cultivars formed pods when pollinated with $C$. pinnatifidum ICC 17276. On the basis of the pod, ovule, and seed formation of the interspecific crosses, we concluded that the chickpea cultivars ICC 4958 and ICCV 96030 and the $C$. pinnatifidum accessions ICC 17269 followed by ICC 17126 and ICC 17200 exhibited good crossability.

To our knowledge, this is the first report of a fully mature $F_{1}$ seed derived from an interspecific cross between cultivated chickpea and $C$. pinnatifidum without using embryo rescue. Our results show that the parents' genotypes affect crossability between $C$. arietinum and $C$. pinnatifidum. The successful development of a mature healthy $F_{1}$ seed from the interspecific ICC $4958 \times$ C. pinnatifidum ICC 17269 cross confirmed the absence of pre- and post-fertilization barriers. Instead, albinism of $F_{1}$ hybrids was the major obstacle hindering geneflow between $C$. pinnatifidum and cultivated chickpea. Embryo abortion occurred after interspecific crosses involving the chickpea cultivar ICCV 96030 and all C. pinnatifidum accessions. Using an ovule culture technique, one albino plantlet was regenerated from the ICCV $96030 \times$ ICC 17269 cross. The interspecific crosses between chickpea cultivar ICCV 10 and $C$. pinnatifidum accessions were unsuccessful due to excessive flower drop and poor pod formation. These variable genotype-specific responses of pod and seed development suggest that more genotypes should be included when testing for cross-compatibility. The cultivated genotypes used here originate from central and southern agrogeographical areas of India. Including more genotypes from other parts of India may be useful for identifying those that are readily crossable with $C$. pinnatifidum, preferably without producing albino progeny.

Although pod and seed formation in crosses between cultivated chickpea and C. pinnatifidum can be improved using various techniques, it will be difficult to improve geneflow between these two species because of the genetic factor that confers albinism in the $F_{1}$ hybrids. These results show that different parental genotype combinations have different crossabilities in inter-specific crosses, indicating that some genetic factors are important for the efficient production of interspecific hybrids involving $C$. pinnatifidum.

\section{Declarations}

\section{Statements \& Declarations}

\section{Funding}

This work was undertaken as part of the initiative "Adapting Agriculture to Climate Change: Collecting, Protecting and Preparing Crop Wild Relatives" which is supported by the Government of Norway (QZA14/0005) and managed by the Global Crop Diversity Trust (http:// www.cwrdiversity.org/). This research was also supported by the CGIAR Research Program on Grain Legumes and Dryland Cereals (GLDC).

\section{Data availability statement}


All data generated for this study is included in the article.

\section{Competing Interests}

The authors have no relevant financial or non-financial interests to disclose.

\section{Author Contributions}

SS planned the study; SAL grew the materials and performed the experiments; SS, SAL, and BK analyzed the data and prepared the manuscript. All the authors read and approved the final manuscript.

\section{References}

Ahmad F, Slinkard AE (2004) The extent of embryo and endosperm growth following interspecific hybridization between Cicer arietinum L. and related annual wild species. Genet. Resour. Crop Evol. 51:765772. https://doi.org/10.1023/B:GRES.0000034580.67728.e4

Badami PS, Mallikarjuna N, Moss JP (1997). Interspecific hybridization between Cicer arietinum and $C$. pinnatifidum. Plant Breed. 116:393-395. https://doi.org/10.1111/j.1439-0523.1997.tb01019.x

Berger JD, Kumar S, Nayyar H, Street KA, Sandhu JS, Henzell JM., Kaur J, Clarke HC (2012) Temperaturestratified screening of chickpea (Cicer arietinum L.) genetic resource collections reveals very limited reproductive chilling tolerance compared to its annual wild relatives. Field Crops Res. 126:119-129. https://doi.org/10.1016/j.fcr.2011.09.020

Canci H, Toker C (2009). Evaluation of annual wild Cicer species for drought and heat resistance under field conditions. Genet. Resour. Crop Evol. 56:1-6. https://doi.org/10.1007/s10722-008-9335-9

Clarke HJ, Kumari M, Khan TN, Siddique KH (2011) Poorly formed chloroplasts are barriers to successful interspecific hybridization in chickpea following in vitro embryo rescue. Plant Cell, Tissue Organ Cult. 106:465-473. https://doi.org/10.1007/s11240-011-9944-4

Collard BCY, Ades PK, Pang ECK, Brouwer JB, Taylor PW (2001) Prospecting for sources of resistance to Ascochyta blight in wild Cicer species. Australas. Plant Pathol. 30:271-276.

https://doi.org/10.1071/AP01036

Croser JS, Ahmad F, Clarke HJ, Siddique KHM (2003) Utilisation of wild Cicerin chickpea improvementprogress, constraints, and prospects. Austral. Jour. Agricult. Res. 54:429-444.

https://doi.org/10.1071/AR02157

FAOSTAT. 2019. http://www.fao.org/faostat/en/\#data/QC. Accessed 14 October 2021.

Infantino A, Porta-Puglia A, Singh KB (1996) Screening wild Cicer species for resistance to fusarium wilt. Plant Dis. 80:42-44. https://doi.org/10.1094/PD-80-0042 
Jukanti AK, Gaur PM, Gowda CLL, Chibbar RN (2012) Nutritional quality and health benefits of chickpea (Cicer arietinum L.): a review. Br. J. Nutr. 108:S11-S26. https://doi.org/10.1017/S0007114512000797

Kashiwagi J, Krishnamurthy L, Upadhyaya HD, Krishna H, Chandra S, Vadez V, Serraj R (2005) Genetic variability of drought-avoidance root traits in the mini-core germplasm collection of chickpea (Cicer arietinum L.). Euphytica, 146:213-222. https://doi.org/10.1007/s10681-005-9007-1

Lulsdorf M, Mallikarjuna N, Clarke H, Taran B, Kharkwal MC (2005) Finding solutions for interspecific hybridization problems in chickpea (Cicer arietinum L.) $4^{\text {th }}$ International Food Legumes Research Conference, New Delhi, India. 44pp.

Mallikarjuna N (1999) Ovule and embryo culture to obtain hybrids from interspecific incompatible pollinations in chickpea. Euphytica 110:1-6. https://doi.org/10.1023/A:1003621908663

Mallikarjuna N, Jadhav D (2008) Techniques to produce hybrid between Cicer arietinum L. x C. pinnatifidum Jaub. Indian J. Genet. Plant Breed. 68:398-405.

Pande S, Ramgopal D, Kishore GK, Mallikarjuna N, Sharma M, Pathak M, Rao JN (2006) Evaluation of wild Cicer species for resistance to Ascochyta blight and Botrytis gray mold in controlled environment at ICRISAT, Patancheru, India. J. SAT Agricult. Res. 2:1-3.

Rao NK, Reddy LJ, Bramel PJ (2003) Potential of wild species for genetic enhancement of some semi-arid food crops. Genet. Resour. Crop Evol. 50:707-721. https://doi.org/10.1023/A:1025055018954

Shah TM, Haq MA, Atta BM, Alam SS, Ali H (2005) Evaluation of Cicer species for resistance to Ascochyta blight. Pak. J. Bot. 37:431-438.

Sharma S, Upadhyaya HD (2019) Photoperiod response of annual wild Cicer species and cultivated chickpea on phenology, growth, and yield traits. Crop Sci. 59:632-

639. https://doi.org/10.2135/cropsci2018.07.0438

Sharma S, Lavale SA, Nimje C, Singh S (2021) Characterization and identification of annual wild Cicer species for seed protein and mineral concentrations for chickpea improvement. Crop Sci. 61:305319. https://doi.org/10.1002/csc2.20413

Stamigna C, Crino P, Saccardo F (2000) Wild relatives of chickpea: Multiple disease resistance and problems to introgression in the cultigen. J. Genet. Breed. 54:213-219.

Stevenson PC, Haware MP (1999) Maackiain in Cicer bijugum Rech. f. associated with resistance to Botrytis grey mould. Biochem. Syst. Ecol. 27:761-767. https://doi.org/10.1016/S0305-1978(99)00023-X

Toker C (2005) Preliminary screening and selection for cold tolerance in annual wild Cicer species. Genet. Resour. Crop Evol. 52:1-5. https://doi.org/10.1007/s10722-005-1743-5 
Toker C, Canci H, Yildirim T (2007) Evaluation of perennial wild Cicer species for drought resistance. Genet. Resour. Crop Evol. 54:1781-1786. https://doi.org/10.1007/s10722-006-9197-y

\section{Tables}

Table 1. Cultivated chickpea and Cicer pinnatifidum accessions used in this study.

\begin{tabular}{|llll|}
\hline Accession identity & Species & Biological status & Country of origin \\
\hline ICC 4958 & Cicer arietinum & Advanced/Improved cultivar & India \\
\hline ICCV 10 & C. arietinum & Cultivated variety & India \\
\hline ICCV 96030 & C. arietinum & Cultivated variety & India \\
\hline ICC 17126 & C. pinnatifidum & Wild species & Turkey \\
\hline ICC 17276 & C. pinnatifidum & Wild species & Syria \\
\hline ICC 17200 & C. pinnatifidum & Wild species & Syria \\
\hline ICC 17269 & C. pinnatifidum & Wild species & Turkey \\
\hline
\end{tabular}

Table 2. Crosses attempted between cultivated chickpea and Cicer pinnatifidum at ICRISAT, Patancheru, India

\begin{tabular}{|lllllll|}
\hline Cross & Female parent & $\begin{array}{l}\text { No. of } \\
\text { pollinations }\end{array}$ & $\begin{array}{l}\text { No. of } \\
\text { matured } \\
F_{1} \text { seeds } \\
\text { obtained }\end{array}$ & $\begin{array}{l}\text { No. of } F_{1} \\
\text { pods } \\
\text { harvested } \\
\text { for ovule } \\
\text { culture }\end{array}$ & $\begin{array}{l}\text { No. of } \\
\text { ovules } \\
\text { cultured }\end{array}$ & $\begin{array}{l}\text { No. of } \\
\text { plantlets } \\
\text { regenerated }\end{array}$ \\
\hline ICCV 10 & (C. pinnatifidum) & & 0 & 9 & 9 & 0 \\
& ICC 17126 & 95 & 0 & 0 & 0 & 0 \\
\cline { 2 - 6 } & ICC 17276 & 55 & 0 & 0 & 0 & 0 \\
\hline ICC 4958 & ICC 17200 & 58 & 0 & 4 & 4 & 0 \\
\hline ICC 17269 & 75 & 0 & 5 & 5 & 0 \\
\hline ICCV 96030 & ICC 17126 & 95 & 0 & 0 & 0 & 0 \\
\hline ICC 17276 & 55 & 0 & 7 & 7 & 0 \\
\hline ICC 17200 & 58 & 1 & 3 & 3 & 0 \\
\hline ICC 17269 & 85 & 0 & 88 & 9 & 0 \\
\hline
\end{tabular}




\section{Figures}

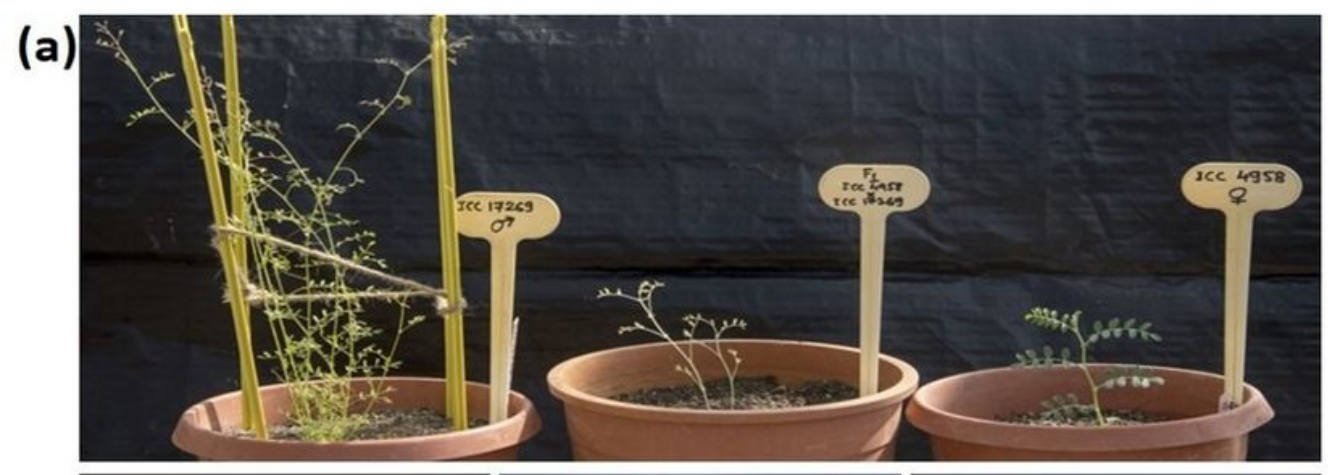

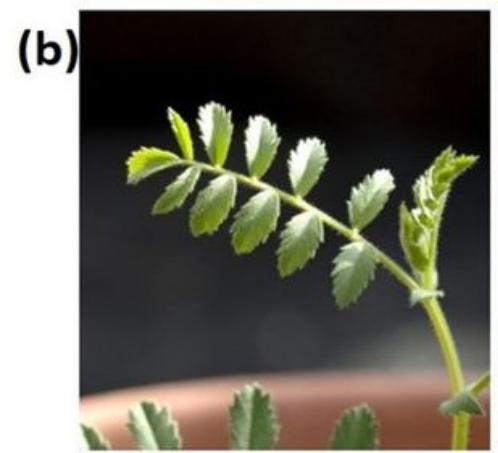

ICC 4958

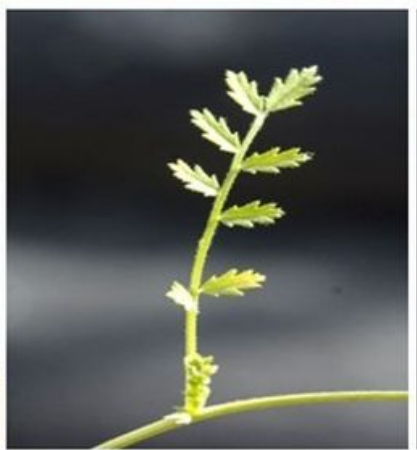

ICC 17269

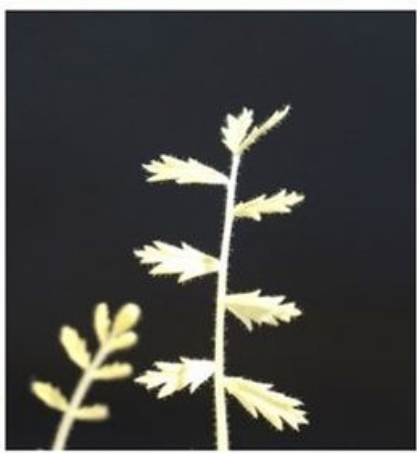

ICC $4958 \times$ ICC 17269

\section{Figure 1}

F1 plant generated from ICC 4958 × ICC 17269; a. Cicer pinnatifidum accession ICC 17269 (left), albino F1 plant (middle), and chickpea cultivar ICC 4958 (right); b. Leaf shape of cultivated parent ICC 4958 (left), wild parent ICC 17269 (middle), and F1 plant resembling wild parent (right). 


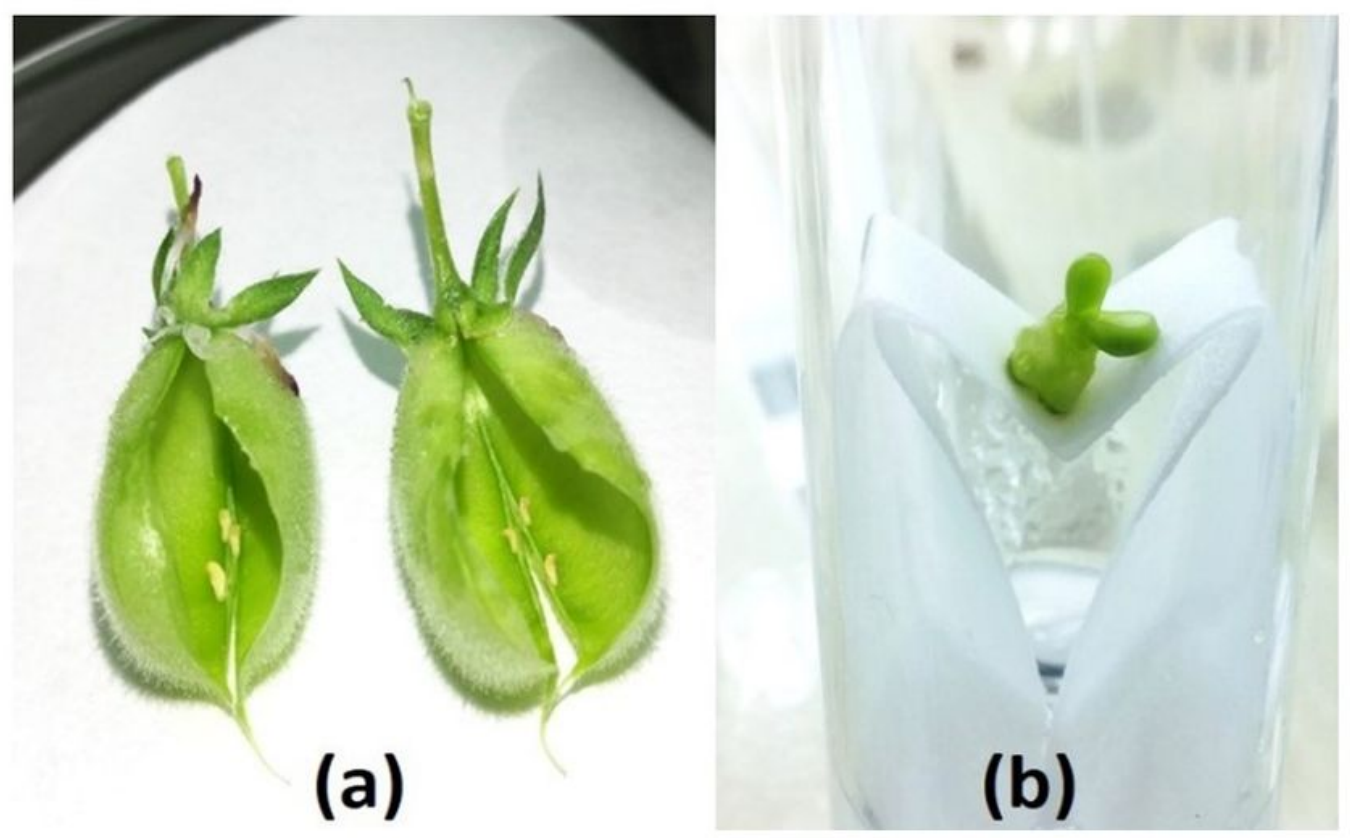

\section{Figure 2}

Ovule culture to rescue hybrid embryo from ICCV 96030 × ICC 17269; a. Well-developed pods containing ovules that failed to develop; b. Ovule cultured in liquid medium. 